practice are considerable, realisable only through harmonisation of the information collected, the method of collection and the systems employed.

Given the urgency in the present situation, the Working Group have agreed to report on their recommendations by the autumn of 1992 . The objectives include recommendations on:

(i) a minimum data set to meet information requirements at all levels, from clinical practice to the Department of Health

(ii) a data structure appropriate for the needs of clinical care and clinical audit

(iii) data comparability and data transfer

(iv) minimal technical specifications.
Membership of the group includes specialty representation and the College's Research Unit. Links have been established with the National Centre for Coding and Classification, the National Case Mix Office, Resource Management Site, the FACE Project, Conferences of Colleges Information Group. The purpose of the present note is to advise members of the College, and other interested groups, of the existence of the Working Group and its remit. Anyone requiring further information is invited to contact the Chairman through the College.

Professor Roy McClelland (Chairman)

\title{
Specialist Section for the Psychiatry of Old Age: Residential Conference Review
}

\author{
Cait Goddard, Consultant in the Psychiatry of Old Age, Bexley Hospital, \\ Kent DA5 2BW; and GianetTa Rands, Senior Registrar, The Maudsley Hospital, \\ London SE5 8AZ
}

The third annual residential conference of the Section was held in Jersey from 5 to 7 March 1992. One hundred and twenty delegates gathered to hear from a range of practitioners. Trainees had a high profile the policy of increasing to a third the proportion of higher trainees intending to be old age psychiatrists is beginning to bear fruit. A whole morning session was devoted to higher training issues ranging from the historical view of the relationship between old age psychiatry (OAP) and geriatrics, to a review of a successful higher training scheme, to innovative hopes for the future in the shape of Individual Performance Review (IPR) and an audit of audit. The senior registrar group's nationwide survey of current higher training experiences was presented.

The Section's support of its trainees was further evident in the fact that three-quarters of the short papers and poster presentations were trainee projects. A wide range of subjects were covered from the psychological sequelae of the Lockerbie disaster in elderly people, to NMR imaging of eggs and brains, to the evolution of the DV system.

The Section adheres to a traditional large group format as its main vehicle for communication. Such large groups have disadvantages - silencing the timid and less experienced and at times not silencing the more aggressively confrontational members. It was noticeable in formal sessions that generational groups had different communication styles - senior members questioning and applauding senior members, trainees listening to and constructively commenting on the work of their contemporaries. At times newer consultants intervened when difficult issues threatened conflict between the generations.

Plentiful free time was scheduled by the organisers and this, as always, was one of the most positive aspects of the residential conference. It was most constructively filled with informal conversation, networking, gossiping and relaxing. Cross-generational communications occurred more easily at such times. As membership of the section increases, itself a reflection of success, it may be that alternative structures for formal sessions could be considered to preserve the benefits of small groups. These could include workshops, working parties and special interest subgroups such as trainees, new consultants, clinical directors and research groups, some of which already exist. These changes could be seen at subsequent residential and quarterly meetings.

A great deal of effort was put into making everyone welcome and the organisation was of the usual high standard we've come to expect of Jean Wales. Our Jersey hosts put on a good show, demonstrating some of the quirks of Jersey life, the problems of organising services on a small island and offering a guided tour of their service. 